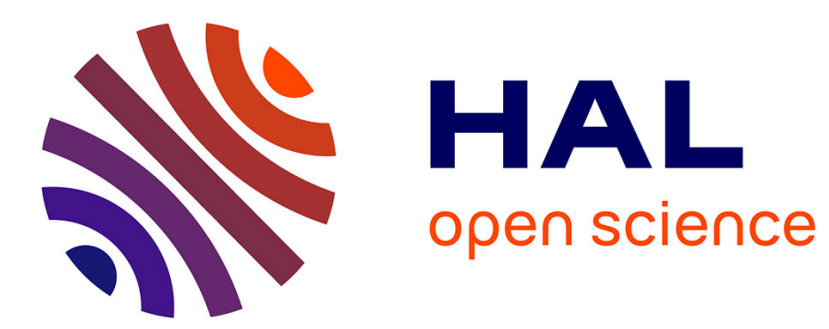

\title{
SURFACE DIFFUSION OF LITHIUM ON THE W(112) PLANE BY FIELD EMISSION SPECTRAL DENSITY ANALYSIS
}

T. Biernat, Ch. Kleint

\section{- To cite this version:}

T. Biernat, Ch. Kleint. SURFACE DIFFUSION OF LITHIUM ON THE W(112) PLANE BY FIELD EMISSION SPECTRAL DENSITY ANALYSIS. Journal de Physique Colloques, 1989, 50 (C8), pp.C8123-C8-128. 10.1051/jphyscol:1989822 . jpa-00229920

\section{HAL Id: jpa-00229920 https://hal.science/jpa-00229920}

Submitted on 1 Jan 1989

HAL is a multi-disciplinary open access archive for the deposit and dissemination of scientific research documents, whether they are published or not. The documents may come from teaching and research institutions in France or abroad, or from public or private research centers.
L'archive ouverte pluridisciplinaire HAL, est destinée au dépôt et à la diffusion de documents scientifiques de niveau recherche, publiés ou non, émanant des établissements d'enseignement et de recherche français ou étrangers, des laboratoires publics ou privés. 
COLLOQUE DE PHYSIQUE

Colloque C8, supplément au $n^{\circ} 11$, Tome 50, novembre 1989

SURFACE DIFFUSION OF LITHIUM ON THE W(112) PLANE BY FIELD EMISSION SPECTRAL DENSITY ANALYSIS

\title{
T. BIERNAT and CH. KLEINT*
}

Institute of Experimental Physics, Wrocław University, 50-205 wrockaw, Cybulskiego 36; USSR

"Sektion Physik, Kar1-Marx-Universität Leipzig, DDR-7010 Leipzig, Linnéstrasse 5, D.R.G.

\begin{abstract}
The spectral density functions w(f) of the field-emission flicker noise of lithiun adsorbed on the tungsten (112) plane were determined at different temperatures in a probe-hole field emission microscope. By an analysis in terms of the Timm and van der Zíl model the surface diffusion coefficients have been obtained and their temperature dependence reveals the surface diffusion energies. For the two coverages of $c=0.38$ and 0.75 irvestigated their values could be determined to be $B=0.56$ and $1.08 \mathrm{EV}$, respectively. The diffusivity prefactors were also calculated. The results are compared with those
\end{abstract} obtained for the w(112)K system.

\section{1 - INTRODUCTION}

Alkali metal adsorption on metals is a subject of long-standing and current interest $/ 1 /$ and much effort has been made with different surface spectroscopies to investigate its properties. Surface diffusion is important for many processes but only a few parameters were obtained for lithium on single planes on transition metals /2,3/. The flicker noise or fluctuation methods / $\$ 4 /$ are advantageous in allowing easily to determine the coverage and even the directional dependence $/ 5,6 /$ though a certain palarization contribution by the high voltage needed is unavoidable. From potassium investigations we know of a strong effect of the coverage /7/ and of surface structure /8/. Noise measurements of the spectral density in dependence on coverage of the same $w(112) \mathrm{Li}$ system $/ 9 /$ show clearly the influence of coherent and incoherent adlayer structures on the adatom mobility. The results presented here illustrate the applicability of the technique but can give only an example of the surface diffusion parameters for two selected coverages.

\section{2 - EXFERIMENTAL}

A field emission microscope (FEM) of the Miller probe-hole type was used to measure the current fluctuations from the central part of the (112) plane of a tungsten single crystal tip covered with a lithium submonolayer. The lithium source consisted of a Li zeolite placed on a resistively heated tantalum sheet. The temperature of the emitter was kept constant by means of a stabilized emitter loop current which was calibrated earlier.

The field emission current was analysed between $25 \mathrm{~Hz}$ and 20 kHz by a frequency spectrometer (Echtzeitanalysator 01012, Messelektronik, Dresden). More experimental details can be fourd in ref../9\%.

The fljcker noise spectral density functions $w(f)$ were measured in dependence on temperature (above room temperature) for some Li concentrations. The chosen coverages were obtained by heating the emitter covered with a thick layer of 1 ithium - -i.e. by thermal desorption of Li from the W(112) plane. The coverages were determined by neasuring the voltage at a constant collector current from the w(112) plane with and without lithium. This allows to calculate the work function, and we obtain the adsorbate 
concentration by taking into account the dependence of the work function versus lithium deposition doses which was calibrated by the concentration ratio $c=n_{L i} / n_{w(112)}$ in ref./2i (see also ref./9/).

\section{$3-$ RESULIS}

The temperature dependence of the spectral density function is illustrated in $f i g s .1$ and $z$ which correspond to $c=0.75$ and 0.38 , respectively. (Other spectra at intermediate temperatures and the same coverages not shown here fit well into the general trend to be described below.) The increase of the emitter temperature leads to a change of the W(f) shape in the investigated frequency range. At room temperature (and slightly above) $W(f)$ can be represented by one straight 1 ine in a double logarithmic scale and described by the equation $w(f) \times f^{-E}$ (figs. $\left.1 \mathrm{a}, \mathrm{b} ; 2 a\right)$.
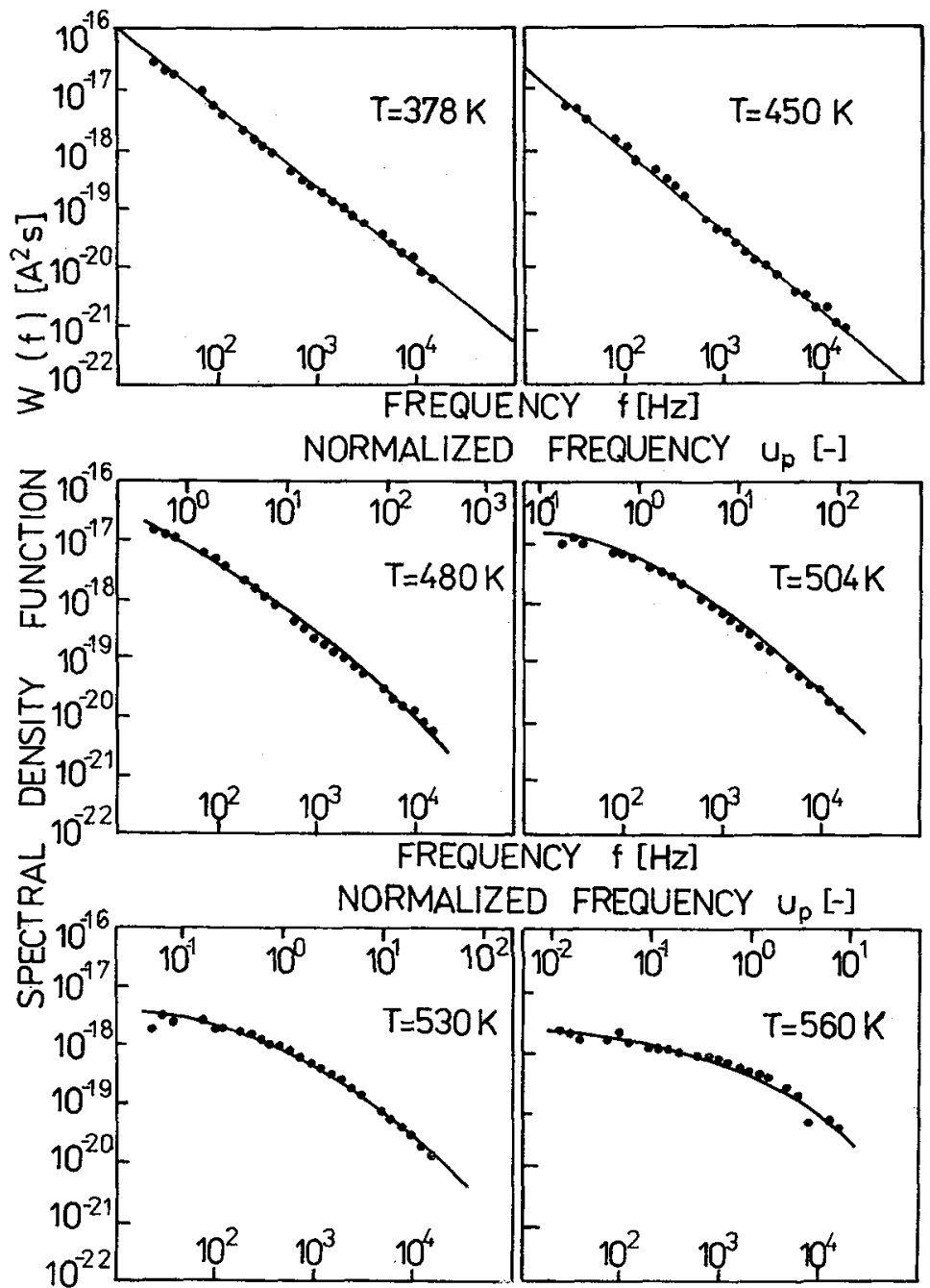

FREQUENCY $f[\mathrm{~Hz}]$

Fig. 1 - Experimental spactral density functions at different temperatures for

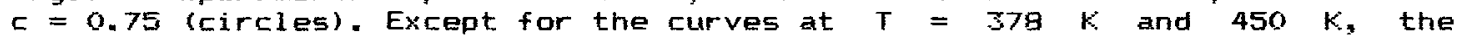
experimental points are fitted by theoretical curves of the Timm and van der Ziel model. 


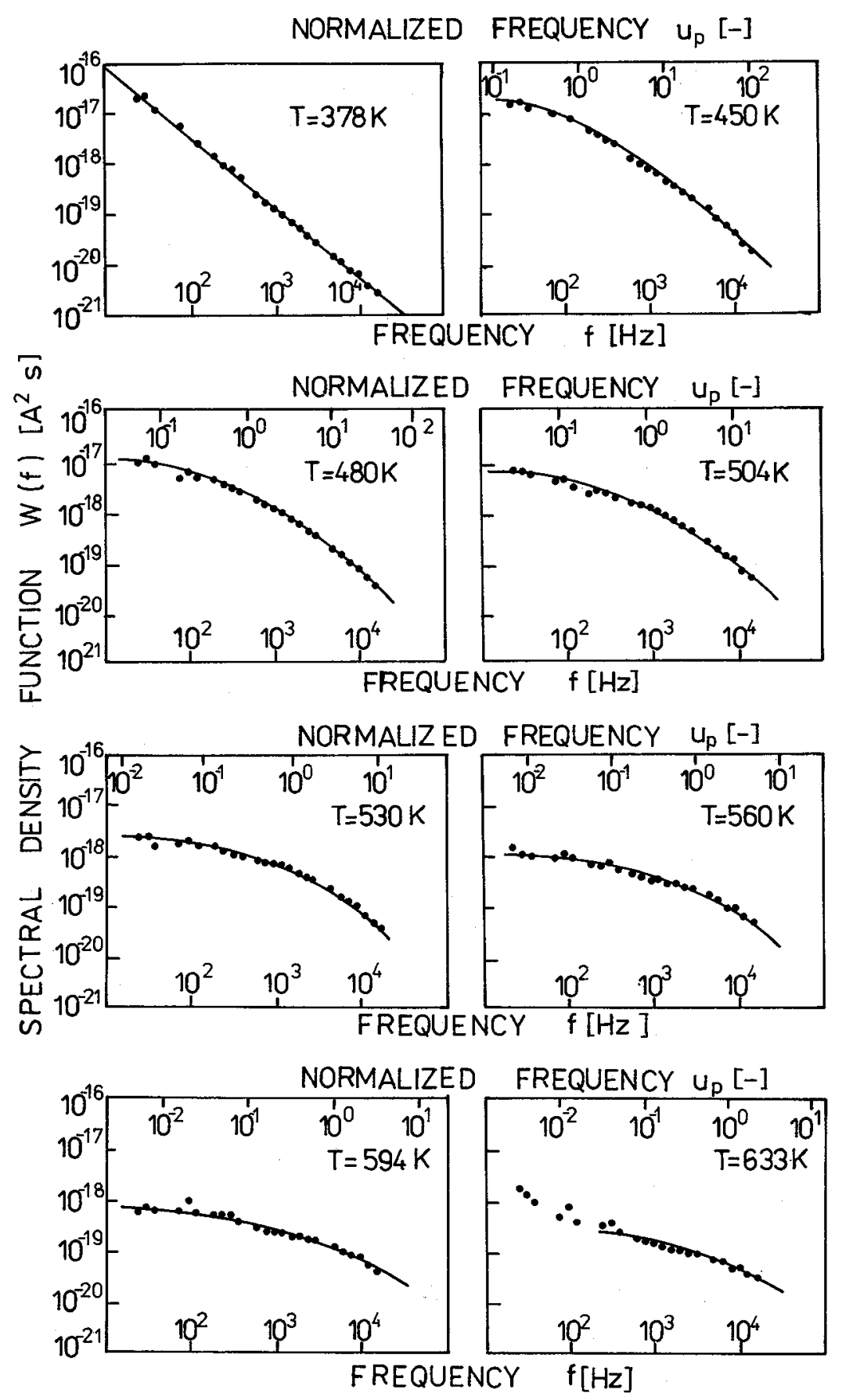

Fig:2. Experimental spectral density functions at different temperatures for $c=0.38$ (circles). Except for the curve at $T=378{ }_{3}$ the experimental points are fitted by theoretical curves of the Timand van der $Z i e i$ model. 
For the higher temperatures the experimental points are approximated by the theoretical spectral density function obtained by Timm and van der Ziei /10/ and corrected by Gesley and Swanson /11/. These authors have assumed a model where surface diffusion of the adsorbate on a small circular probe area causes fluctuations in the number of adparticles on this area. The fluctuations are described by the spectral density function $S\left(u_{p}\right.$ ) given by

$$
S\left(u_{p}\right)=C_{F N}\left\langle(\delta N)^{2}\right\rangle r_{p}^{2} p^{-1} T\left(u_{p}\right) \text {. }
$$

where $u_{p}=2 \pi+r_{p}^{2} / D$ is the normalized frequency and $T u_{p}$ an expression composed of Kelvin functions $(C P / 6 /)$. (SSN) $\left.{ }^{2}\right\rangle$ is the mean-square fluctuation of the adparticle number on the probed area with radius $r$ " $D$ is the, surface diffusion caefficient and $C_{F N}$ the Fowier-Nordheim term.

The temperature above which the change of the w(t) shape can be observed depends on the lithium coverage. For example at the high concentration of $c \approx$ 2.45 a temperature increase above room temperature leads already to a decrease of the lithium concentration on the w(112) plane (according to the voltage at constant collector current). At a temperature of about $504 k$ approaches unity. A visible change of the w(f) shape took place for $C=0.75$ and $c=0.38$ at $T=460 \mathrm{~K}$ and $\mathrm{T}=400 \mathrm{~K}$, respectively.

\section{4 - EVALUATION AND_DISCUSSION}

By compering the experimental spectral density function wif) with theory the diffusion coefficient has been calculated. As it was done in ref./7/ for the $u-k$ system the frequency scales that correspond to the experimental wif? (lower scale in figs.1 and 2) were compared with the frequency scale that corresponds to the dimensionless normalized "frequency" ${ }^{p}$ defined above (upper scale). From this comparison and taking the probed area radius to be about $10^{-6} \mathrm{~cm}$ the diffusion coefficient D can be obtained. Figs. 3 and 4 illustrate its temperature dependence for the W(f) examples shown in figs. 1 and $z$, respectiveiy. The data is well represented by a straight line fit.

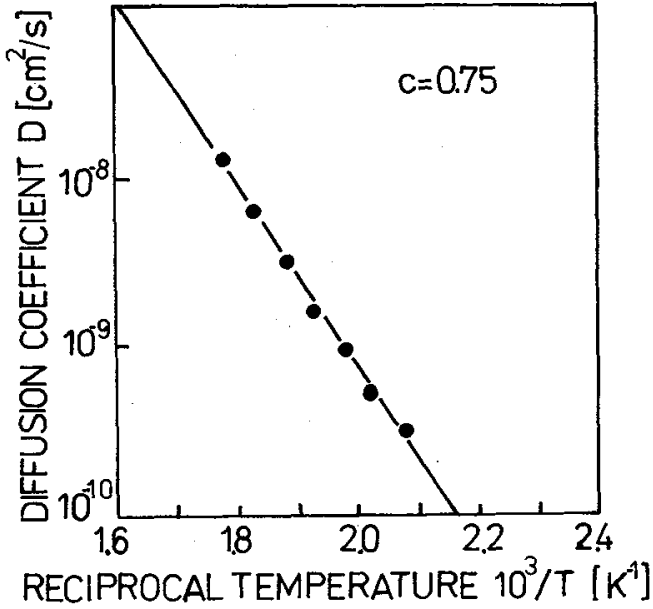

Fig. 3 - Arrhenius plot of the diffusion coefficients at a concentration of $c=0.75$ $(\mathrm{Q}=1.0 \mathrm{~B} \mathrm{eV})$.

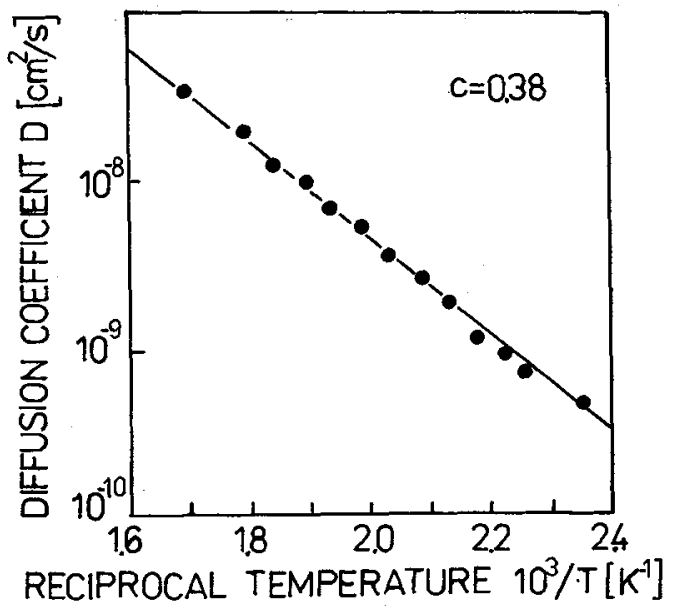

Fig.4 - Arrhenius plot of the diffusion coefficients at a concentration of $c=0.38$ $(\mathrm{Q}=0.56 \mathrm{eV})$. 
From the Arrhenius plots of the diffusion coefficients we have the surface diffusion activation energy $Q=0.56 \mathrm{eV}$ and the prefactor $D_{0}=2.4 \times 10^{-3} \mathrm{~cm}^{2} / 5$ at the $L i$ concentration of $c=0.38$. At the higher coverage $(c=0.75$ ) the respective values are considerably higher: $\theta=1.0 \mathrm{eV}$ and $\mathrm{D}_{0}=6.3 \times 10^{-1} \mathrm{~cm}^{2} / 5$. The Li activation energies are in general larger than those for potassium on the W(112) plane $/ 7 /$ which appears to be a natural consequence of the smaller size of $L i$ atoms or ions. (This is not true, however, for the first value of $Q_{L i}=0.56 \mathrm{eV}$ at a coverage where $Q_{\mathrm{K}}$ was found to be somewhat higher/7/.1. A detailed comparison requires more Li data especially at different coverages than are available at present.

According to figs. 1 and 2 the experimental spectral density functions are fitted rather well by the theoretical curves of the Timn and van der Ziel model ( $S_{\infty}$ ) except in the lower temperature range. There $W(f)$ can be deseribed by the spectrum $(f) \propto f^{-\epsilon}$ which reveals a straight 1 ine in a double logarithmic plot. With increasing temperature small discrepancies develop at the high frequency part of the measured spectra (only a part of them is shown in $f i g s .1$ and 2 ). Finally the curves of the two-dimensional (2D) fluctuation model $S_{\infty}(c f . / 11 /)$ describe the spectra as mentioned above. It seems that

this temperature dependence can be explained in the following way: Near room temperature we observe in fact a one-dimensional diffusion along the rows of the bcc (112) plane of tungsten. The adequate 10 -model gives the spectrum $\mathrm{S}^{\mathrm{kD}}$ derived by Gesley and Swanson /11/. This function platted in fig.1 af ref./11/ versus the normalized frequency $u_{p}=\omega r_{p}^{2} p$ is not exactly a straight line but can be approximated for, say, $1 \frac{1}{2}$ or 2 frequency decades by straight lines with a slope between $\varepsilon=1$ and 1.5 . Considering the approximate description of the real diffusion by the 1D-model one can in fact explain the spectra by these arguments.

At higher temperatures, however, we find some deviations at low frequericies (fig. 2h) and another mechanism might be responsible for them. We expect a phase transition from the ordered phase to the disordered but the theories developed so far disregard this transition. The beginning of an observable substrate atom mobility might also show up at these temperatures $/ 12 /$.

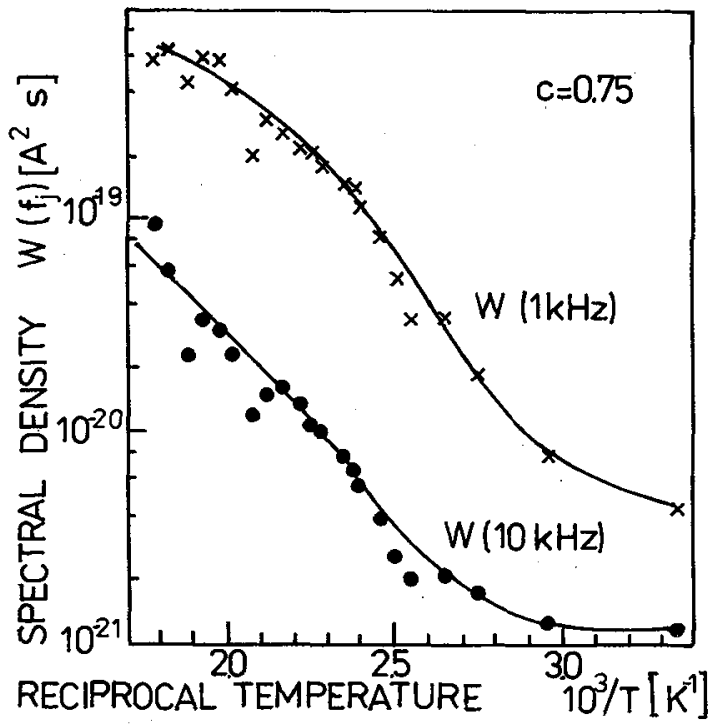

Fig 5 - Spectral densities W(f ${ }_{j}$ ) versus reciprocal temperature for a concentration of $c=0.75$.

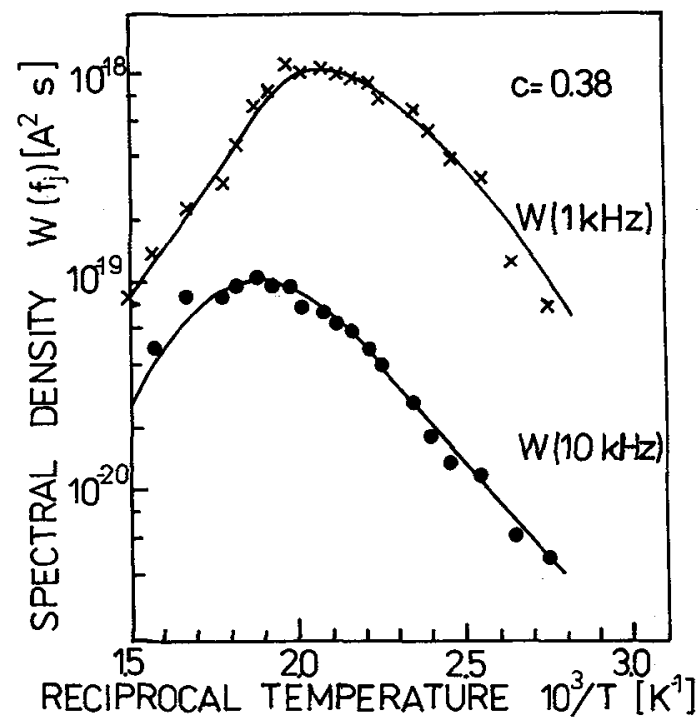

Fig.b - Spectral densities $W\left(f_{j}\right.$ ? versus reciprocal temperature for a concentration of $c=0.38$. 
The temperature dependence of the spectral densities (figs. 5 and 6 ) reflects the general trend of the complete spectra: with rising temperature the noise power also increases but we have at the same time diminishing low frequency parts of the $W(f)^{\prime} s$ according to the change from the 1D- to the 2Dspectra, namely $S^{1 D}$ changing to $5_{\infty}$. Therefore, at the coverage of $c=0.38$

( $f$ ig-6) we abserve at first a $\mathrm{W}(1 \mathrm{kHz}$ ) maximum followed by the $\mathrm{W}(10 \mathrm{kHz})$

maximum. A similar behaviour at $c=0.75$ (fig. 5) is expected at higher temperatures because of the following reason. From the frrhenius plots of the diffusion coefficients we found the surface diffusion activation energy $Q=$ 0.56 and $1.08 \mathrm{EV}$ at the $\mathrm{Li}$ concentration of $c=0.38$ and 0.75 respectively. Therefore one expects in fact the maximum of fig. 5 at higher temper atures.

It is interesting to note that a similar dependence of the spectral densities with reciprocal temperature was observed also for clean /12/ and heavily covered /13/ tungsten tips as well as for epitaxial K crystals/14/. The lithium investigations and their interpretation in terms of surface diffusion presented above may also explain the general fluctuation behaviour of the three mentianed surfaces (Cp also/15/) if the number of mobile atoms is not too large.

\section{ACKNOWLEDGEMENTS}

Discussions with Frofessor R.Meclewski on this subject are gratefully acknowl edged.

Work sponsored by the Folish Ministry of National Education within the Central Project of Basic Research CPBF 01.08.A.

\section{FEFEFENCES}

/ $1 /$ 5oth WE-Heraeus-Seminar: Physical and Chemical Aspects of Alkali Metal Adsorption. Bad Honnef, Febr. 1989.

( 2/ V.K.Medvedev, A.G. Naumovets and T.F.Smereka, Surface Sci. 3.4 (1973) 368.

/ 3/ A.G.Naumovets and Yu.S.Vedula, Surface Sci. Reports 4 (1984) 365.

/ 4/ Ch.kleint, Surface Sci. 200 (1988) 472.

/5/ R.Ełaszczyszyn and Ch.Kleint, Surface Sci. 171 (1986) 615.

$/ 6 / 3$. Beben, Ch.Kleint and Fi.Meclewski, J. Fhysique 48 (1978) C6 - 545.

$/ 7 / \mathrm{J}$.Eeben, Ch. Kleint and F.Meclewski, Z. Phys. E 69 (1997) 319.

/ 8/ R. Błaszczyszyn and Ch.Kleint. Appl. Fhys. A_46 (1989) 145.

/ 9/ T.Eiernat and Ch.kleint, Appl. Phys. A (in press).

/10/ G.W.Timm and A.yan der Ziel, Physica 32 (1966) 1333.

/11/ M.A.Gesley and L.W. Swanson, Phys.Fev. $\bar{B} 32$ (1985) 7703.

$112 /$ T.Biernat and Ch.kleint, Appl. Surface $5 c i .27(1987) 411$.

113/ T.Eiernat and Ch.Kleint, Acta Fhys. Folon. A 69 (1986) 507.

114 T.Biernat and Ch.kleint, Surface Sci. 127 (1983) 498.

/15/ Ch.kleint, Ann. Fhys. (Leipzig) 38 (19̄i) 305. 